of 'Wolf Hall', I cannot but think that there must be many occasions when dentists should not need to go through such rigorous investigation so that, as so frequently happens, $s /$ he is found to have learnt from their mistakes and be free to go back to work without sanctions.

K. Winstone, Longfield, Kent

DOI: 10.1038/sj.bdj.2015.255

\section{Fighting the stupidity}

Sir, I think we need some clarification regarding the exact implication of standard 1.7.2: '...If you work in a practice that provides both NHS (or equivalent health service) and private treatment (a mixed practice), you MUST make clear to your patients which treatments can be provided under the NHS (or equivalent health service) and which can only be provided on a private basis.'

As far as I am aware there is no set list of treatments that can be provided under NHS arrangements and it is down to an individual's interpretation of "clinically necessary and clinically cost effective' to quote the departing Chief Dental Officer for England. Before the 2006 fiasco (contract), we all knew the limitations of the NHS provisions and if we wanted to step outside these we asked for approval from the DRO service. Since the abolition of this body the system has been woolly at best. This leads to confusion in both patients and practitioners, in fact the whole Which? campaign of late could have been headed off by getting this ludicrous situation remedied.

I humbly suggest that every single NHS practitioner could potentially be found guilty of violating this standard completely innocently if, at an FTP hearing, the 'expert' witness decrees his opinion to differ from your own. This is a ridiculous situation for us, as professionals, to be in. I implore the BDA who represent us as a trade union to remedy this and publically call on the Department of Health to clarify their expectations. We risk our livelihoods at the whim of someone whose opinion may differ from our own. If I am mistaken then I would be grateful to see a copy of the full list of NHS approved treatments, as even the GDC could not provide me with one. If anyone out there can help please contact me, my address is on the GDC website (surprisingly!).

This is one battle the BDA should fight. They should partner with the GDC and Which? to produce clarity, as it is good for both patients and practitioners and would massively reduce the amount of stress within the profession, and confusion for patients. It would be a real win/ win. We cannot hit an undefined standard, it's an impossibility! The BDA has recently shown its teeth and if we want dentistry to be taken seriously we need to keep fighting the stupidity that currently surrounds the NHS situation.

P. Woodhouse,

by email

DOI: 10.1038/sj.bdj.2015.256

\section{DENTAL EDUCATION}

\section{Galactic microscopes}

Sir, I am continually surprised and disappointed regarding the number of recent graduates who seem not to use magnification as a matter of course for operative dentistry procedures.

Recently, whilst delivering various topics in the postgraduate arena to cohorts of dentists less than two years out of dental school, a show of hands in a group of around 12 (from a hybrid mix of training hospitals nationally) to the question as to "who uses magnification (loupes or microscope) routinely as a part of delivering procedures to patients?' produces a dismal three or four positives at most. Loupes are alien and microscopes are outer galaxy! Dreadful!

A similar result is forthcoming in that no one has ever shown them how to appropriately use a close support dental nurse to effectively help to deliver what are operator-demanding procedures less haphazardly. The parameters of the 1950s and even earlier hold sway.

Both of these areas are examples of where the long overdue use of even simple innovation will transform the way in which the microsurgical procedures of operative dentistry are delivered for patients and team. Can someone currently involved in teaching undergraduates operative techniques explain to me why this has gone unchanged for 40 or 50 years or more? Is there any surgical speciality that does not now use magnification routinely (let alone one that is $90 \%$ or more microsurgery - ie dentistry!)?

Nothing perhaps will evolve in any effective way unless the undergraduate schools address this. Maybe they do and graduates are not convinced? It also begs the question - do their teachers use magnification? Please enlighten me. Are these simple conclusions and my concerns totally wrong?

K. F. Marshall, by email DOI: 10.1038/sj.bdj.2015.257 